\title{
Distinct Electrostatic Interactions Govern the Chiro-Optical Properties and Architectural Arrangement of Peptide-Oligothiophene Hybrid Materials
}

Robert Selegård, Zeinab Rouhbalchsh, Hamid Shirani, Leif J ohansson, Patrick Norman, Mathieu Linares, Daniel Aili and Peter Nilsson

The self-archived postprint version of this journal article is available at Linköping University Institutional Repository (DiVA):

http:/ / urn.kb.se/ resolve?urn=urn:nbn:se:liu:diva- 141931

N.B.: When citing this work, cite the original publication.

Selegård, R., Rouhbalchsh, Z., Shirani, H., J ohansson, L., Norman, P., Linares, M., Aili, D., Nilsson, P., (2017), Distinct Electrostatic Interactions Govern the Chiro-Optical Properties and Architectural Arrangement of Peptide-Oligothiophene Hybrid Materials, Macromolecules, 50(18), 7102-7110. https:// doi.org/ 10.1021/ acs.macromol.7b01855

Original publication available at:

https:// doi.org/ 10.1021/acs.macromol.7b01855

Copyright: American Chemical Society

http:// pubs.acs.org/ 
Title: Distinct electrostatic interactions governs the chiro-optical properties and architectural arrangement of peptide-oligothiophene hybrid materials

Robert Selegård, ${ }^{\dagger}$ Zeinab Rouhbakhsh,${ }^{\dagger}$ Hamid Shirani, ${ }^{\ddagger}$ Leif B. G. Johansson, ${ }^{\ddagger}$ Patrick Norman, ${ }^{\|}$Mathieu Linares, ${ }^{\|}$Daniel Aili, ${ }^{\dagger}$ and K. Peter R. Nilsson ${ }^{*}+$

†Division of Molecular Physics, Department of Physics, Chemistry and Biology, Linköping University, SE-581 83 Linköping, Sweden.

Division of Chemistry, Department of Physics, Chemistry and Biology, Linköping University, SE-581 8 Linköping, Sweden

"Division of Theoretical Chemistry and Biology, School of Biotechnology, KTH Royal Institute of Technology, SE-106 91 Stockholm, Sweden

*Corresponding author E-mail: petni@ifm.liu.se 
The development of chiral optoelectronic materials are of great interest due to their potential of being utilized in electronic devices, biosensors and artificial enzymes. Herein, we report the chiral-optical properties and architectural arrangement of optoelectronic materials generated from non-covalent self-assembly of a cationic synthetic peptide and five chemically defined anionic pentameric oligothiophenes. The peptide-oligothiophene hybrid materials exhibit a three dimensional ordered helical structure and optical activity in the $\pi-\pi^{*}$ transition region that are observed due to a single chain induced chirality of the conjugated thiophene backbone upon interaction with the peptide. The latter property is highly dependent on electrostatic interactions between the peptide and the oligothiophene, verifying that a distinct spacing of the carboxyl groups along the thiophene backbone is a major chemical determinant for having a hybrid material with distinct optoelectronic properties. The necessity of the electrostatic interaction between specific carboxyl functionalities along the thiophene backbone and the lysine residues of the peptide, as well as the induced circular dichroism of the thiophene backbone, was also confirmed by theoretical calculations. We foresee that our findings will aid in designing optoelectronic materials with dynamic architectonical precisions, as well as offer the possibility to create the next generation of materials for organic electronics and organic bioelectronics. 


\section{INTRODUCTION}

The development of chiral conjugated oligo- and polythiophenes is of great interest due to their potential of being utilized in optoelectronic devices, biosensors and artificial enzymes. ${ }^{1-8}$ Through the addition of an optically active substituent in the 3-position of the thiophene ring or at the terminal $\alpha$-positions of the conjugated backbone, an optical activity in the $\pi$ - $\pi^{*}$ transition region derived from the main-chain chirality when the polymer chains are forming supramolecular, $\pi$-stacked self-assembled aggregates are achieved. ${ }^{5,9-16}$ Studies, using optically inactive conjugated polythiophenes that become chiral upon addition of a chiral guest, have also implied that an induced chirality of the conjugated backbone can be a result of an acidbase complexation between the achiral side-chain substituent and the chiral guest, rendering a one-handed helical structure with a preferred twist reflecting the stereochemistry of the chiral guest. ${ }^{17-20}$ Such a single chain induced chirality of the conjugated backbone has also been observed for polythiophenes having $L$ - or $D$-amino acid side chain functionalities in the $\beta$ positions of the thiophene moieties. ${ }^{21,22}$

Proteins, DNA and polysaccharides frequently show helical conformations that contribute both to their three-dimensional structure and their specific functions. Likewise, peptide $\pi$ electron conjugates, having highly ordered structures and distinct optoelectronic properties, have also been developed through covalent ligation of oligothiophenes to peptide building blocks. ${ }^{23-26}$ However, these covalently linked hybrid materials are mainly assembled in organic solvents and from a biological perspective, assembly in physiological conditions would be preferable to preserve a native like structure of the biomolecular element. In this regard, induced chirality in optically inactive oligo- and polythiophenes upon interaction with double stranded DNA, distinct polysaccharides or helical peptides have been reported. ${ }^{26-29}$ In addition, hybrid supramolecular complexes have been generated through self-assembly of optically inactive anionic polythiophenes and a cationic synthetic random coil peptide. ${ }^{30,31}$ When associating, 
these hybrid molecules displayed distinct chiro-optical properties as well as specific threedimensional ordered structures. Hence, chiral optoelectronic material having the threedimensional ordered structure of a biomolecule and the electronic properties of polythiophenes can be derived from self-assembly of optically inactive anionic polythiophenes and a cationic synthetic random coil peptide. However, the water-soluble polythiophenes in these studies ${ }^{30,31}$ were generated from random polymerization of different monomeric building blocks that render polydispersed materials. This lack of chemical precision in the optoelectronic constituent might limit the applications of these hybrid materials and the development of chemically defined oligothiophenes that can interact with the synthetic peptides in a complementary fashion will be advantageous.

A library of anionic pentameric luminescent conjugated oligothiophenes (LCOs) was recently reported $^{32,33}$ and herein we studied the optical- and structural properties of hybrid materials created from self-assembly of five chemically related optically inactive anionic LCOs (Figure 1) with a synthetic cationic peptide denoted JR2K (Figure 1). The complexation of the anionic LCOs and the cationic peptide generated materials having a three dimensional ordered helical structure and optical activity in the $\pi-\pi^{*}$ transition region. The latter property was highly dependent on electrostatic interaction between specific carboxyl functionalities along the thiophene backbone and the lysine residues of the peptide. Thus, minor chemical modification of the LCOs could be utilized to tune the interactions with the synthetic peptide. Overall, our findings will aid in designing optoelectronic materials with dynamic architectonical precisions that can be implemented within organic electronics and organic bioelectronics.

\section{RESULTS AND DISCUSSION}

Absorption- and emission spectra of pentameric LCOs mixed with JR2K. To investigate the interaction between the respective LCO and JR2K, we first compared the optical characteristics of the LCOs in $20 \mathrm{mM}$ phosphate buffer $\mathrm{pH} 7.0$ and the mixture of LCOs/JR2K 
in the same buffer. All the LCOs displayed a red-shift of the absorption maximum when mixed with JR2K (Figure 2), suggesting that the interaction with the peptide will induce a planarization and an increased effective conjugation length of the thiophene backbone. Interestingly, the red-shifts of the absorption maxima for the LCOs upon interaction with JR2K is the opposite compared to the blue-shift previously reported for the polymeric analogue, polythiophene acetic acid (PTAA) (Figure 1a). ${ }^{30}$ Thus, all the anionic pentameric oligothiophenes interact with JR2K in a different fashion compared to PTAA. From a chemical perspective, all the thiophene rings of PTAA have acetic acid substituents in the $\beta$-position, whereas all the pentameric LCOs have one or more unsubstituted thiophene rings along the backbone and this lack of substitutions might induce a different pattern of electrostatic interaction between the chemically defined LCOs and the peptide.

The interaction with JR2K also altered the fluorescence properties of the LCOs. In a similar fashion as described above, the emission maxima of the LCOs were red-shifted upon interaction with JR2K. p-FTAA only showed a minor red-shift, whereas the red-shifts were more pronounced for the other LCOs (Figure 2). A similar red-shifted emission has also been observed for the trimer-based anionic polythiophene, tPTAA (Figure 1a) when interacting with JR2K. ${ }^{30}$ In contrast, analogous to the shift in absorption, PTAA mixed with JR2K was reported to display a blue-shifted emission. ${ }^{31}$ tPTAA has the same central trimeric thiophene core as the LCOs, whereas PTAA display acetic acid substituents on all thiophene rings. Thus, the disparity in the optical response between the anionic oligo- and polythiophenes is most likely a result of the distribution of the anionic carboxyl groups along the thiophene backbone. A distinct spacing of carboxyl groups along the thiophene backbone has previously been shown to be a major chemical determinant for achieving optimal interactions between LCOs and protein aggregates, the pathological hallmarks of many neurodegenerative diseases. ${ }^{34,35}$ Overall, the photo- 
physical assessments revealed that the anionic LCOs interact with the cationic peptide and that this interaction induce distinct optical signatures from the LCOs.

\section{Surface plasmon resonance, fluorescence and dynamic light scattering studies of the} interaction between the LCOs and JR2K. In order to investigate the interaction between the LCOs and JR2K in more detail, a set of biophysical techniques, including surface plasmon resonance (SPR), fluorescence and dynamic light scattering (DLS) was applied. In order to evaluate the binding affinities between the LCOs and JR2K using SPR, a second peptide was synthesized, JR2KK-Az. In this peptide the valine in position 22 was exchanged for an azide functionalized Lysine residue, providing means for anchoring the peptide to a dibezocyclooctyne (DBCO) modified dextran surface using a strain-promoted azide-alkyne cycloaddition reaction. The sensorgrams (Figure S1), obtained by injecting 10-1500 $\mu \mathrm{M}$ pulses of LCOs, clearly showed a concentration dependent dose response and could be fitted to a steady state affinity model assuming a 1:1 stoichiometry (Figure 3). All peptide-LCO combinations showed dissociation constants in the low mM range. p-HTAA which is the least substituted LCO showed significantly faster dissociation kinetics compared to the other LCOs probably deriving from the low electrostatic interaction in this LCO-peptide combination (Figure S1).

As all the LCOs showed a red-shift of the absorption- and excitation maxima $\left(\operatorname{Exc}_{\max }\right)$ when interacting with the peptide, the ratio of the intensity of the emitted light at the excitation maximum for bound LCO, $\operatorname{Exc}_{\max }$ (bound), and the excitation maximum for unbound LCO, $\operatorname{Exc}_{(\max )}($ unbound), could be applied to estimate the dissociation constant for the respective LCO bound to JR2K. A similar approach was previously applied to determine the dissociation constant for LCOs bound to protein aggregates. ${ }^{35,36}$ The binding curves for the distinct LCOs 
towards JR2K were generated by plotting the ratio $\operatorname{Exc}_{\max }($ bound)/Exc(max) $($ unbound) against the JR2K concentration. $\mathrm{K}_{\mathrm{d}}$ values were obtained by fitting to a sigmoid function (Hill1 function) and all the LCO displayed dissociation constants in the low micromolar or submicromolar range (Figure 3). The higher $\mathrm{K}_{\mathrm{d}}$ values obtained by SPR, could most likely be a consequence of immobilizing the peptide in a dextran matrix. As previously shown by Enander et. al. ${ }^{37}$, JR2K showed a lower affinity for the interaction with a complementary negatively charged peptide when immobilized in a dextran matrix compared to when the interaction took place in solution.

DLS measurements also confirmed the interaction between JR2K (Figure 4). Individually, the peptide and the LCOs produced very low scattering intensities $(<2 \mathrm{kHz})$ and the resulting correlation functions showed no presence of aggregates of any kind except for p-HTAA that appears to form micelles. When combining JR2K and LCOs slightly higher scattering intensities ranging from about 2.5 to $10 \mathrm{kHz}$ and an increase in lag times were seen, strongly indicating that the molecules interact and form a complex. However, the scattering intensities were still relatively low which strongly indicates that none of the combinations form larger aggregates. Overall, the biophysical measurements using three different techniques, SPR, fluorescence and DLS, confirmed that all the anionic pentameric LCOs were interacting with the positively charged peptide JR2K in a similar fashion.

Circular dichroism spectra of pentameric LCOs mixed with JR2K. As previously reported, oligo- and polythiophenes having optically active substituents at distinct positions along the conjugated backbone exhibit a split-type induced $\mathrm{CD}$ (ICD) in the $\pi-\pi^{*}$ transition region. ${ }^{5,9-16}$ The CD spectra of the anionic pentameric oligothiophenes after $10 \mathrm{~min}$ of incubation in pure buffer solution (20 mM sodium phosphate, $\mathrm{pH}$ 7.0) are shown in Figure 5a. All the LCOs have optically inactive substituents, the carboxyl functionalities, and no characteristic circular 
dichroism pattern in the $\pi-\pi^{*}$ transition region was observed. In contrast, after the addition of an equal amount $(30 \mu \mathrm{M})$ of JR2K to p-FTAA, split-type induce ICD in the $\pi-\pi^{*}$ transition region were induced (Figure 5b), suggesting that the interactions between the negatively charged carboxyl groups of the LCOs and the positively charge amine groups of the lysine side chains in the peptide is responsible for the induced chirality of the thiophene backbone. The observed ICD is most observed due to a single chain induced chirality of the conjugated thiophene backbone upon interaction with the peptide, since all of the optical data (Figure 2), as well as the DLS measurement (Figure 4) showed no presence of aggregates. Such a single chain induced chirality of the conjugated backbone has also been observed for polythiophenes having $L$ - or $D$-amino acid side chain functionalities in the $\beta$-positions of the thiophene moieties, ${ }^{21,22}$ as well as for optically inactive anionic polythiophenes mixed with a cationic synthetic random coil peptide. ${ }^{30}$ The ICD was decreased when adding only half the amount of JR2K and did not increase upon addition of twice the amount of peptide, verifying that the stoichiometry of the JR2K/p-FTAA is most likely 1:1 (Figure 5b). When comparing the ICDs for all the LCOs mixed with JR2K, the signal was most pronounced for p-FTAA and HS-72, and a distinct ICD was also observed for HS-117 (Figure 5c). In contrast, for p-HTAA no observable ICD was obtained, indicating that an interaction between the $\alpha$-terminal carboxyl groups extending the thiophene backbone and the peptide is necessary for achieving an induced chirality of the thiophene backbone that are observed as an ICD in the $\pi-\pi^{*}$ transition region. p-FTAA and HS-72 have $\alpha$-terminal carboxyl groups directly extending the thiophene backbone, whereas these groups are lacking for p-HTAA and separated from the conjugated backbone by a methylene bridge for HS-117. Thus, the presence as well as a correct localization of these groups are a major chemical determinant for achieving a strong ICD from the anionic pentameric LCOs when mixed with JR2K. As previously reported, the polydipsersed analogue, PTAA, displayed an ICD correlated to a right-handed helical form of polythiophene when 
mixed with JR2K. ${ }^{30}$ However, in contrast to PTAA, the shape and sign of the ICD pattern observed for the LCOs are characteristic of a left-handed helical form of polythiophenes, ${ }^{10,11}$ verifying that the LCOs interacts in a different fashion than PTAA with JR2K.

The CD spectrum in the far-UV region (Figure 5d) showed that JR2K predominantly is random coil in phosphate buffer $(20 \mathrm{mM}, \mathrm{pH} 7.0)$. In contrast, the CD spectra in the far-UV region for all the LCO-JR2K solutions displayed a strong positive CD signal at 190-195 nm and strong negative peaks at 208 and 222 nm, indicative of a helical structure (Figure 5d). Hence, the interaction between JR2K and all the LCOs will induce an ordered helical structure of the peptide. The helical structures are most likely stabilized by hydrophobic interactions between the nonpolar amino acids and the hydrogen-bonded ion pair complex between the negatively charged carboxyl groups of the oligothiophene side chains and the positively charged lysine $(\mathrm{K})$ groups of the peptide side chains. Opposed to the observation that the $\alpha$-terminal carboxyl groups extending the thiophene backbone are necessary for achieving an ICD in the $\pi-\pi^{*}$ transition region, the LCO induced formation of the helical structure of JR2K seems to be independent of these carboxyl groups. Although, for HS-72 there is a change in the ratio of the mean residue ellipticities at 222 and $208 \mathrm{~nm}$ compared with the other LCOs and a similar observation has been seen in a previous study using a zwitterionic polythiophene derivative and a heterodimeric four-helix bundle. ${ }^{26}$ In comparison to the other LCOs, HS-72 has the 3thiophene acetic acid substitution on the central thiophene ring, suggesting that that this chemical modification of the substitution pattern will alter the shape of the helices. The change in ratio observed for HS-72 indicates that JR2K adopts $3^{10}$-helices instead of $\alpha$-helices when mixed with HS-72.

Theoretical calculations. To better understand the structure of the helix-loop-helix polypeptide, JR2K, and its interaction with the two LCOs, p-FTAA and p-HTAA, we modeled 
three systems (free JR2K in water, JR2K + p-FTAA, and JR2K + p-HTAA) using classical force field molecular dynamics (MD) simulations. For the simulation of JR2K alone, significant structural changes in the protein backbone was observed when examining the selected snapshots extracted from the MD trajectory (Figure S2). In addition, the interactions with the two LCOs (p-HTAA and p-FTAA) stabilized the structure of JR2K as can be seen from the evolution of the Radius of gyration ( $\mathrm{Rg}$ ) and the root mean square deviation (RMSD) of the protein backbone during the MD simulation (Figures S3 and S4, respectively).

Since p-FTAA present the largest ICD signal of all the LCO tested when in interaction with JR2K, we decided to perform a detailed analysis of its adsorption sites. It is interesting to note that the probe is quite mobile on the surface of JR2K and that several adsorption sites could be identified. In Table 1, we have summarized the four most probable adsorption sites, defined as sites where the LCO spent the most time during the dynamics. In addition, data for the time spent at each adsorption site as well as the corresponding averaged stabilization energies decomposed into Coulombic and van der Waals contributions were also estimated (Table 1). The binding is mainly due to Coulombic interaction between the COO- groups of p-FTAA and the positively charged Lysine groups of JR2K whereas the contribution from van der Waals interactions is quite marginal.

Representative snapshots of the four different sites are presented in Figure 6 together with the averaged ECD spectra calculated for 150 snapshots of each site. For each of the four sites, the p-FTAA molecule present a strong ICD signal coming from a deformation of the backbone of the polythiophene showing a bisignated CD response signal that is in excellent agreement with the experimental spectra. Indeed we were able to accurately reproduce the band characteristic showing a $-/+$ couplet as due to the low lying excited states. The discrepancy between experiment and theory regarding the excitation energy can be explained by the use of an approximate functional and simplified model system obtained by removing the $\mathrm{COO}^{-}$and 
$\mathrm{CH}_{2} \mathrm{COO}^{-}$groups and neglecting the environment in the $\mathrm{CD}$ calculations. All these computational issues are well understood and, at increased computational costs, it is possible to improve the description of the electronic structure as well as to include the environment by means of a polarizable embedding model. However, it fall outside the scope of the present study to pursue such investigations since we are merely interested in revealing the underlying microscopic reasons for the ICD and not to quantitatively reproduce the experimental CD signal. The adopted level of theory is a suitable compromise to qualitatively correct describe the dichroism in p-FTAA as induced by peptide interactions and we can identify the deformations of the polythiophene core that give rise to the observed ICD as shown in Figure 6.

\section{CONCLUSIONS}

In conclusion, materials with distinct chiral-optical properties and architectural arrangement have been generated from non-covalent self-assembly of a cationic synthetic peptide and chemically defined anionic pentameric oligothiophenes. The materials exhibited a three dimensional ordered helical structure and optical activity in the $\pi-\pi^{*}$ transition region. The latter property was greatly dependent on the distinct spacing of carboxyl groups along the thiophene backbone and is thus a major chemical determinant for having a hybrid material with distinct optoelectronic properties. The necessity of the electrostatic interaction between specific carboxyl functionalities along the thiophene backbone and the lysine residues of the peptide, as well as the induced circular dichroism of the thiophene backbone, was also confirmed by theoretical calculations. We foresee that our findings will aid in designing novel materials that can be utilized for developing optoelectronic devices, biosensors and artificial enzymes. 


\section{METHODS}

LCO synthesis. The synthesis of p-FTAA, p-HTAA, HS-72 and HS-117 were described as reported previously. ${ }^{32,34}$

$\begin{array}{lllll}\text { Peptide } & \text { synthesis. } & \text { The } & \text { peptides } 2 \mathrm{~K} & \left(\mathrm{H}_{2} \mathrm{~N}-\right.\end{array}$ NAADLKKAIKALKKHLKAKGPVDAAQLKKQLKQAFKAFKRAG-COOH) and JR2KK ( ${ }_{2} \mathrm{~N}-\mathrm{NAADLKKAIKALKKHLKAKGPKDAAQLKKQLKQAFKAFKRAG-COOH)} \mathrm{were}$ synthesized on a Quartet automated peptide synthesizer (Protein Technologies, Inc) using standard fluroenylmethoxycarbonyl (Fmoc) chemistry. To allow for a site-selective modification of position 22 in JR2KK, the side chain of Lys-22 was protected by an allyloxycarbonyl (Alloc). The peptides were synthesized in a $0.1 \mathrm{mmol}$ scale using Fmoc-GlyWang (Iris biotech Gmbh) as solid support. Each coupling was performed using a fourfold excess of O-(7-benzotriazole-1-yl)-1, 1, 3, 3-tetra-methyluronium tetrafluoroborate (TBTU, Iris biotech $\mathrm{Gmbh}$ ) as activator and an eightfold excess of N,N-diisopropylethylamine (DIPEA, Iris biotech Gmbh) as base. A fourfold excess of amino acid (Iris biotech Gmbh) was used in each coupling and Fmoc deprotection of the coupled amino acid was accomplished by treatment of piperidine in DMF (1:4, Applied Biosystems). Site specific modification of Lys-22 in JR2KK was achieved by deprotection of the alloc group by treatment with three equivalents of tetrakis(triphenylphosphine)palladium(0) $\left(\mathrm{Pd}\left(\mathrm{PPh}_{3}\right)_{4}\right)$ in $15 \mathrm{~mL}$ trichloromethane/ acetic acid/ $\mathrm{N}$-methylmorpholine $(17: 2: 1)$ for 3 hours in a $\mathrm{N}_{2}$ atmosphere. The resin was sequentially washed with $20 \mathrm{mM}$ diethyldithiocarbamic acid in DMF and $30 \mathrm{mM}$ DIPEA in DMF, followed by DMF and DCM. An azide functionality was introduced by reacting the resin with 3azidopropionic acid (1 mmol), N-hydroxysuccinimide (1 mmol), N-ethyl-N'-(3dimethylaminopropyl)carbodiimide hydrochloride $(1 \mathrm{mmol})$ and DIPEA $(2.5 \mathrm{mmol})$ in DCM (10 mL) for 18 hours affording JR2KK-Az. The peptides were cleaved from their solid support by exposure to a solution containing TFA (trifluoroacetic acid), water and TIS 
(triisopropylsilane) $(95: 2.5: 2.5) 15 \mathrm{mLg}^{-1}$ of resin for 2 hours followed by filtration and evaporation of the solvent. The crude peptides were precipitated twice in cold diethylether and then lyophilized. Purification of the crude peptides were carried out using a 30 minute gradient of $25-35 \%$ aqueous isopropanol with $0.1 \%$ TFA on an ACE 5 C-8 column ( $250 \times 21.2 \mathrm{~mm})$ attached to a semi-preparative HPLC system (Dionex). The identity of the purified peptides were confirmed by MALDI-TOF MS using an $\alpha$-cyano-4-hydroxycinnamic acid matrix.

Synthesis of 3-azidopropionic acid. 3-bromopropionic acid (30 mmol) and sodium azide (60 mmol) was dissolved in water $(50 \mathrm{~mL})$ and allow to react for $72 \mathrm{~h}$. The reaction mixture was acetified with $\mathrm{HCL}(1 \mathrm{M})$ and extracted with $\mathrm{EtO}_{2}$ affording the product as a transparent oil which was used without further purification. ${ }^{1} \mathrm{H} \mathrm{NMR}\left(300 \mathrm{MHz}, \mathrm{CDCl}_{3}\right) \delta 11.18(\mathrm{~s}, 1 \mathrm{H}), 3.57$ $(\mathrm{t}, \mathrm{J}=6.3 \mathrm{~Hz}, 2 \mathrm{H}), 2.63(\mathrm{t}, \mathrm{J}=6.3 \mathrm{~Hz}, 2 \mathrm{H}) ;{ }^{13} \mathrm{C} \mathrm{NMR}\left(75.5 \mathrm{MHz}, \mathrm{CDCl}_{3}\right) \delta 33.8,46.5,177.4$.

Optical characterization of the LCOs towards JR2K. JR2K was dissolved in buffer (20 mM phosphate, $\mathrm{pH}$ 7.0) to a final concentration of $60 \mu \mathrm{M}$. The LCOs was dissolved in de-ionized water to a concentration of $1.5 \mathrm{mM}$ LCOs. The respective thiophene based pentameric ligand was mixed with JR2K solution or buffer (20 mM phosphate, $\mathrm{pH} 7.0)$ to generate the desired concentrations of LCO and JR2K, and incubated for $10 \mathrm{~min}$. The absorption-, excitation- and emission spectrum for each probe were collected using a Tecan Infinite M1000 Pro microplate reader (Tecan, Männedorf, Switzerland) and CD spectra were recorded with an Chirascan (Applied Photophysics, Leatherhead, U.K.) using a $5 \mathrm{~mm}$ or a $1 \mathrm{~cm}$ quartz cell. Titration experiments adding different concentration of JR2K to a fixed concentration of LCOs (500 nm) were also performed as described above. 
Dynamic light scattering (DLS). DLS measurements were performed on an ALV/DLS/SLS5022F system (ALV Gmbh) using a HeNe laser at $632.8 \mathrm{~nm}$ with $22 \mathrm{~mW}$ output power. All samples were dissolved in phosphate buffer (20 mM phosphate, $\mathrm{pH} 7.0)$, filtered using a PVDF filter and tempered to $21.5^{\circ} \mathrm{C}$. All measurements were repeated 10 times and the collected data averaged.

Surface plasmon resonance (SPR). SPR measurements were carried out on a Biacore 3000 instrument (Biacore $\mathrm{AB}$ ) using a sensor chip with a carboxymethylated dextran matrix (CM5, GE Healthcare). Experiments were performed at $25{ }^{\circ} \mathrm{C}$ and at a flowrate of $10 \mu \mathrm{L} \mathrm{mL}{ }^{-1}$. All samples were dissolved in the running buffer (PB $20 \mathrm{mM}, \mathrm{pH} 7.0$ ), filtered and sample injections lasted for 6 min. Two flow cells (FCs) were used in the experimental setup, one functionalized with JR2KK-Az (FC2) and one without as a reference channel (FC1). The FCs were prepared accordingly; a mixture of NHS $(50 \mathrm{mM})$ and EDC $(250 \mathrm{mM})$ were allowed to react with the carboxylgroups in the dextran matrix directly followed by dibenzocyclooctyneamine (DBCO) (150 $\mu \mathrm{M}, 10 \%$ DMSO, Sigma Aldrich), ethanolamine (1M, Biacore AB) and then JR2KK-Az (150 $\mu \mathrm{M}$ in PB) in FC2. Lastly, remaining DBCO were pacified in both FCs by an injection of ethanolazide $(1 \mathrm{M})$. LCOs $(10-1500 \mu \mathrm{M})$ were injected in a randomized order and the FCs were washed in between with Glycine-HCL buffer (10 mM pH 3.0, Biacore AB), $\mathrm{NaOH}(50 \mathrm{mM}$, Biacore AB), SDS (0.5\% w/v, BIAdesorb solution 1, Biacore AB), $\mathrm{NaOH}$ followed by Glycine-HCL buffer. Data where evaluated using BIAevaluation software. Signals from the reference channel were subtracted from the LCO response and fittings were perform using a steady state affinity model assuming a 1:1 stoichiometry.

Computational details. In the present work, the four-helix bundle protein was used as the starting structure of the polypeptide which have the PDB entry 1MFT of the Protein Data 
Bank, ${ }^{38}$ at the highest resolution $(2.5 \AA)$. In order to prepare model for polypeptide, the initial structure for the 42-amino-acid helix-loop-helix polypeptide, JR2K was constructed in Discovery Studio. ${ }^{38}$ The PBD structure of the four helix bundle was cut to one helix loop and the amino acids were replaced with the one of JR2K, (NAADLKKAIKALKKHLKAKGPVDAAQLKKQLKQAFKAFKRAG). ${ }^{38}$ All calculations were performed using GROMACS package v.4.5.5. ${ }^{39}$ For JR2K we adopted the standard CHARMM force field ${ }^{40}$ and for p-HTAA and p-FTAA we used a refined CHARMM forcefield that we have published previously. ${ }^{41,42}$ The protonation state of the JR2K was adjusted in order to mimic a pH value of 7.0. All Lys, Asn and Arg residues were positively charged, and Asp and Gly residues were negatively charged, so JR2K has a positive net charge of +11 in $\mathrm{pH}$ 7.0.

The MD simulations were carried out using periodic boundary conditions to generate a cubic simulation box defined with the dimensions of $7 \times 7 \times 7 \mathrm{~nm}^{3}$. The polypeptide JR2K was placed in the box, and subsequently the polypeptide was solvated with TIP3P water model. ${ }^{43}$ To neutralize the system, an appropriate number of $\mathrm{Cl}^{-}$and $\mathrm{Na}^{+}$ions were added to the box in each system: $11 \mathrm{Cl}^{-}$atoms for JR2K, $11 \mathrm{Cl}^{-}$and $2 \mathrm{Na}^{+}$for JR2K+p-HTAA and $11 \mathrm{Cl}^{-}$and $4 \mathrm{Na}^{+}$for $\mathrm{JR} 2 \mathrm{~K}+\mathrm{p}-\mathrm{FTAA}$. The steepest-descent algorithm was used to minimize the energy of each system and to relax the water molecules. The simulations were carried out at the NPT ensemble with a time step of $0.001 \mathrm{ps}$. The temperature of the system was kept constant at $300 \mathrm{~K}$ with a Nosé-Hoover thermostat, ${ }^{44}$ and the pressure was coupled to a Parrinello-Rahman barostat at 1 atm. ${ }^{45,46}$ The temperature and pressure time constants of the coupling were 0.2 and $0.1 \mathrm{ps,}$ respectively. The LINCS algorithm was applied to constrain bond lengths. ${ }^{47}$ The simulations were carried out first for $100 \mathrm{~ns}$ to equilibrate the system before a production run of $1 \mu \mathrm{s}$ in order to investigate structural changes. To simplify the discovery of binding sites for p-FTAA in 
interaction with JR2K, a simulation with position restrain condition was done, in which the polypeptide structure was restrained at a fixed position. ${ }^{48}$

For each of the four sites identified, 150 snapshots were selected with sufficient time (at least $5 \mathrm{ps}$ ) in between them as to avoid any structure correlation and their geometries were optimized using the steepest-descent algorithm. Then the JR2K, waters and ions were removed and for the p-FTAA molecule, the $\mathrm{COO}^{-}$end group and the $\mathrm{CH}_{2} \mathrm{COO}^{-}$central groups were replaced by hydrogen atoms and methyl groups, respectively. For each of these geometries, we computed a circular dichroism spectrum using the CAM-B3LYP functional in combination with the 6$31+\mathrm{G}(\mathrm{d})$ basis set with use of the Gaussian software. ${ }^{49}$ The first 20 excited states were considered and a Gaussian function with a full width at half maximum of $0.2 \mathrm{eV}$ was used for each excited state to broaden the spectra. Finally, the spectra were averaged for each binding site.

\section{ACKNOWLEDGEMENT}

Our work were financed by the Knut and Alice Wallenberg Foundation (RS, ZR and DA), the Swedish Foundation for Strategic Research (RS, ZR, DA, HS and KPRN), and the Swedish

Government Strategic Research Area in Materials Science on Functional Materials at Linköping University (Faculty Grant SFO Mat LiU No 2009 00971).

\section{REFERENCES}

(1) Lemaire, M.; Delabouglise, D.; Garreau, R.; Guy, A.; Roncali, J. J. Chem. Soc., Chem. Commun. 1988, 658-661.

(2) Kotkar, D.; Joshi, V.; Ghosh, P. K. J. Chem. Soc., Chem. Commun. 1988, 917-918. 
(3) Roncali, J.; Garreau, R.; Delabouglise, F.; Garnier, F.; Lemaire, M. Synth. Met. 1989, 28, 341-348.

(4) Andersson, M.; Ekeblad, P. O.; Hjertberg, T.; Wennerström, O.; Inganäs, O. Polymer Commun. 1991, 32, 546-548.

(5) Bouman, M. M.; Havinga, E. E.; Janssen, R. A. J.; Meijer, E. W. Mol. Cryst. Liq. Cryst. 1994, 256, 439-448.

(6) Bouman, M. M.; Meijer, E. W. Adv. Mater. 1995, 7, 385-387.

(7) Bidan, G.; Guillerez, S.; Sorokin, V. Adv. Mater. 1996, 8, 157-160.

(8) Andreani, F.; Angiolini, L.; Caretta, D.; Salatelli, E. J. Mater. Chem. 1998, 8, 1109-1111.

(9) Langeveld-Voss, B. M. W.; Bouman, M. M.; Christiaans, M. P. T.; Janssen, R. A. J.; Meijer, E. W. Polym. Prepr. 1996, 37, 499-500.

(10) Langeveld-Voss, B. M. W.; Janssen, R. A. J.; Christiaans, M. P. T.; Meskers, S. C. J.; Dekkers, H. P. J. M.; Meijer, E. W. J. Am. Chem. Soc. 1996, 118, 4908-4909.

(11) Langeveld-Voss, B. M. W.; Christiaans, M. P. T.; Janssen, R. A. J.; Meijer, E. W. Macromolecules 1998, 31, 6702-6704.

(12) Langeveld-Voss, B. M. W.; Janssen, R. A. J.; Meijer, E. W. J. Mol. Struct. 2000, 521, 285301.

(13) Goto, H.; Yashima, E.; Okamoto, Y. Chirality 2000, 12, 396-399.

(14) Henze, O.; Feast, W. J.; Gardebien, F.; Jonkheijm, P.; Lazzaroni, R.; Leclere, P.; Meijer, E. W.; Schenning, A. P. H. J. J. Am. Chem. Soc. 2006, 128, 5923-5929.

(15) Schmid, S.; Mena-Osteritz, E.; Kopyshev, A.; Bäuerle, P. Org. Lett. 2009, 11, 5098-5101. (16) Digennaro, A.; Wennemers, H.; Joshi, G.; Schmid, S.; Mena-Osteriz, E.; Bäuerle, P. Chem. Comm. 2013, 49, 10929-10931.

(17) Yashima, E.; Matsushima, T.; Okamoto, Y. J. Am. Chem. Soc. 1997, 119, 6345-6359.

(18) Yashima, E.; Maeda, K.; Okamoto, Y. Nature 1999, 399, 449-451. 
(19) Maeda, K.; Okada, S.; Yashima, E.; Okamoto, Y. J. Polym. Sci., Part A: Polym. Chem. 2001, 39, 3180-3189.

(20) Ishikawa, M.; Maeda, K.; Yashima, E. J. Am. Chem. Soc. 2002, 124, 7448-7458.

(21) Nilsson, K. P. R.; Andersson, M. R.; Inganäs, O. J. Phys.: Condens. Matter 2002, 14, 10011-10020.

(22) Nilsson, K. P. R.; Olsson, J. D. M.; Konradsson, P.; Inganäs, O. Macromolecules 2004, $37,6316-6321$.

(23) Matmour, R.; De Cat, I.; George, S. J.; Adriaens, W.; Leclère, P.; Bomans, P. H. H.; Sommerdijk, N. A. J. M.; Gielen, J. C.; Christianen, P. C. M.; Heldens, J. T.; van Hest, J. C. M.; Löwik, D. W. P. M.; De Feyter, S.; Meijer, E. W.; Schenning, A. P. H. J. J. Am. Chem. Soc., 2008, 130, 14576-14583.

(24) Kumar, R. J.; MacDonald, J. M.; Singh, T. B.; Waddington, L. J.; Holmes, A. B. J. Am. Chem. Soc., 2011, 133, 8564-8573.

(25) Herderline, A. M. A.; Tovar, J. D. Bioconjugate Chem. 2015, 26, 2290-2302.

(26) Ewbank, P. C.; Nuding, G.; Suenaga, H.; McCullough, R. D.; Shinkai, S. Tetrahedron Lett. 2001, $42,155-157$.

(27) Ho, H. A.; Boissinot, M.; Bergeron, M. G.; Corbeil, G.; Dore, K.; Boudreau, D.; Leclerc, M. Angew. Chem. Int. Ed. 2002, 41, 1548-1551.

(28) Sanji, T.; Kato, N.; Tanaka, M. Org. Lett. 2005, 8, 235-238.

(29) Nilsson, K. P. R.; Rydberg, J.; Baltzer, L.; Inganäs, O. Proc. Natl. Acad. Sci. USA 2003, $100,10170-10174$.

(30) Nilsson, K. P. R.; Rydberg, J.; Baltzer, L.; Inganäs, O. Proc. Natl. Acad. Sci. USA 2004, $101,11197-11202$.

(31) Wigenius, J.; Björk, P.; Hamedi, M.; Aili, D. Macromol. Biosci. 2010, 10, 836-841. 
(32) Åslund, A.; Sigurdson, C. J.; Klingstedt, T.; Grathwohl, S.; Bolmont, T.; Dickstein, D. L.; Glimsdal, E.; Prokop, S.; Lindgren, M.; Konradsson, P.; Holtzman, D. M.; Hof, P. R.; Heppner, F. L.; Gandy, S.; Jucker, M.; Aguzzi, A.; Hammarström, P.; Nilsson, K. P. R. ACS Chem. Biol. 2009, 4, 673-684.

(33) Simon, R. A.; Shirani, H.; Åslund, K. O. A.; Bäck, M.; Haroutunian, V.; Gandy, S.; Nilsson, K. P. R. Chemistry 2014, 20, 12537-12543.

(34) Klingstedt, T.; Shirani, H.; Mahler, J.; Wegenast-Braun, B. M.; Nyström, S.; Goedert, M.; Jucker, M.; Nilsson, K. P. R. Chemistry 2015, 21, 9072-9082.

(35) Herrmann, U. S.; Schütz, A. K.; Shirani, H.; Huang, D.; Saban, D.; Nuvolone, M.; Li, B.; Ballmer, B.; Åslund, A. K.; Mason, J. J.; Rushing, E.; Budka, H.; Nyström, S.; Hammarström, P.; Böckmann, A.; Caflisch, A.; Meier, B. H.; Nilsson, K. P. R.; Hornemann, S.; Aguzzi, A. Sci. Transl. Med. 2015, 7, 299ra123.

(36) Johansson, L. B. G.; Simon, R.; Bergström, G.; Eriksson, M.; Prokop, S.; Mandenius, C. F.; Heppner, F. L.; Åslund, A. K.; Nilsson, K. P: R. Biosens. Bioelectron. 2015, 63, 204-211. (37) Enander, K.; Aili, D.; Baltzer, L.; Lundström, I.; Liedberg, B. Langmuir 2005, 21, 24802487.

(38) Lahr, S. J.; Engel, D. E.; Stayrook, S. E.; Maglio, O.; North, B.; Geremia, S.; Lombardi, A.; DeGrado, W. F. J. Mol. Biol. 2005, 346, 1441-1454.

(39) Berendsen, H. J. C.; van der Spoel, D.; van Drunen, R. Comput. Phys. Commun. 1995, 91, 43-56.

(40) MacKerell Jr., A. D.; Bashford, D.; Bellott, M.; Dunbrack Jr., R. L.; Evanseck, J. D.; Field, M. J.; Fischer, S.; Gao, J.; Guo, H.; Ha, S.; Joseph-McCarthy, D.; Kuchnir, L.; Kuczera, K.; Lau, F. T. K.; Mattos, C.; Michnick, S.; Ngo, T.; Nguyen, D. T.; Prodhom, B.; Reiher, W. E.; Roux, B.; Schlenkrich, M.; Smith, J. C.; Stote, R.; Straub, J.; Watanabe, M.; WiórkiewiczKuczera, J.; Yin, D.; Karplus, M. J. Phys. Chem. B 1998, 18, 3586-3616. 
(41) Sjöqvist, J.; Linares, M.; Lindgren, M.; Norman, P. Phys. Chem. Chem. Phys. 2011, 13, 17532-17542.

(42) Sjöqvist, J.; Linares, M.; Mikkelsen, K. V.; Norman, P. J. Phys. Chem. A 2014, 118, 34193428.

(43) Jorgensen, L.; Chandrasekhar, J.; Madura, J. D.; Impey, R. W.; Klein, M. L. J. Chem. Phys. 1983, 79, 926-935.

(44) Nosé, S.; Klein, M. L. Mol. Phys. 1983, 50, 1055-1076.

(45) Bussi, G.; Donadio, D.; Parrinello, M. J. Chem. Phys. 2007, 126, 14101-14107.

(46) Parrinello, M.; Rahman, A. J. Appl. Phys. 1981, 52, 7182-7190.

(47) Berendsen, H. J. C.; Postma, J. P. M.; van Gunsteren, W. F.; Hermans, J.; Pullman, B. (Ed.), Intermolecular Forces, Reidel, Dordrecht (1981) 331-342.

(48) Spoel, D. V. D.; Lindahl, E.; Hess, B.; Groenhof, G.; Mark, A. E.; Berendsen, H. J. C. J Comput Chem. 2005, 26, 1701-1718.

(49) Frisch, M. J.; Trucks, G. W.; Schlegel, H. B.; Scuseria, G. E.; Robb, M. A.; Cheeseman, J. R.; Scalmani, G.; Barone, V.; Mennucci, B.; Petersson, G. A.; Nakatsuji, H.; Caricato, M.; Li, X.; Hratchian, H. P.; Izmaylov, A. F.; Bloino, J.; Zheng, G.; Sonnenberg, J. L.; Hada, M.; Ehara, M.; Toyota, K.; Fukuda, R.; Hasegawa, J.; Ishida, M.; Nakajima, T.; Honda, Y.; Kitao, O.; Nakai, H.; Vreven, T.; Montgomery, J. A., Jr.; Peralta, J. E.; Ogliaro, F.; Bearpark, M.; Heyd, J. J.; Brothers, E.; Kudin, K. N.; Staroverov, V. N.; Kobayashi, R.; Normand, J.; Raghavachari, K.; Rendell, A.; Burant, J. C.; Iyengar, S. S.; Tomasi, J.; Cossi, M.; Rega, N.; Millam, J. M.; Klene, M.; Knox, J. E.; Cross, J. B.; Bakken, V.; Adamo, C.; Jaramillo, J.; Gomperts, R.; Stratmann, R. E.; Yazyev, O.; Austin, A. J.; Cammi, R.; Pomelli, C.; Ochterski, J. W.; Martin, R. L.; Morokuma, K.; Zakrzewski, V. G.; Voth, G. A.; Salvador, P.; Dannenberg, J. J.; Dapprich, S.; Daniels, A. D.; Farkas, O.; Foresman, J. B.; Ortiz, J. V.; Cioslowski, J.; Fox, D. J. Gaussian 09, revision D.01; Gaussian, Inc.: Wallingford, CT, 2009. 
FIGURES AND FIGURE LEGENDS

a)

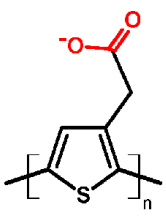

PTAA

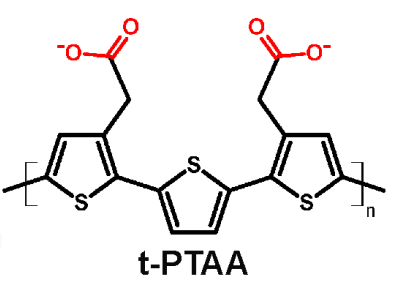

c)
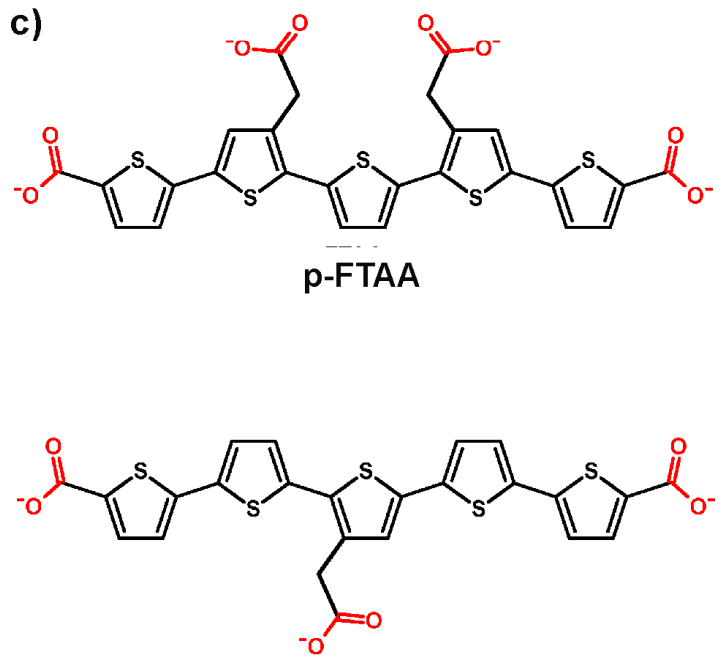

HS-72 b)

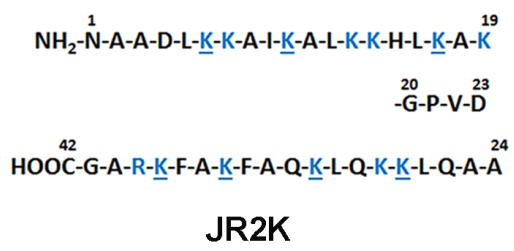<smiles>O=C([O-])Cc1cc(-c2cccs2)sc1-c1ccc(-c2sc(-c3cccs3)cc2CC(=O)O)s1</smiles><smiles>O=C([O-])Cc1ccc(-c2ccc(-c3cc(CC(=O)O)c(-c4ccc(CC(=O)O)s4)s3)s2)s1</smiles>

HS-117

Figure 1. a) Chemical structures of the anionic polythiophenes, PTAA and t-PTAA. b) Amino acid sequence of the cationic peptide JR2K. The positively charged residues lysine $(\mathrm{K})$ and arginine (R) are highlighted in blue. c) Chemical structures of the anionic oligothiophenes pFTAA, p-HTAA, HS-72 and HS-117. The negatively charged carboxyl groups of the poly- and oligothiophenes are highlighted in red. 
a)

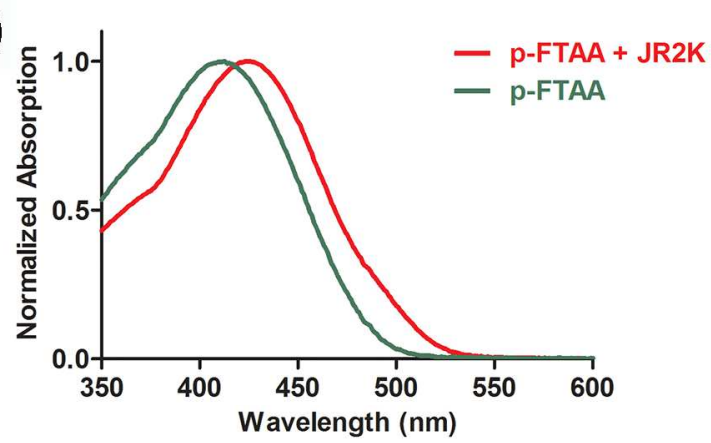

b)

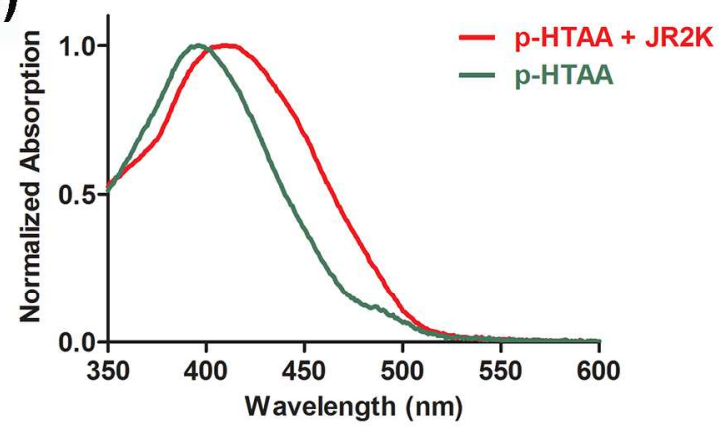

c)

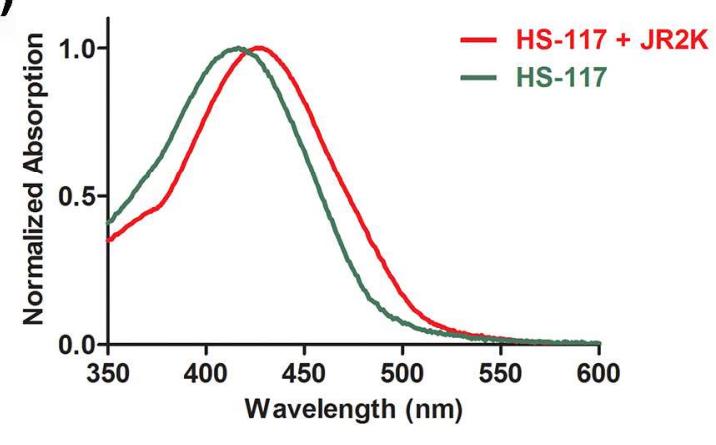

d)

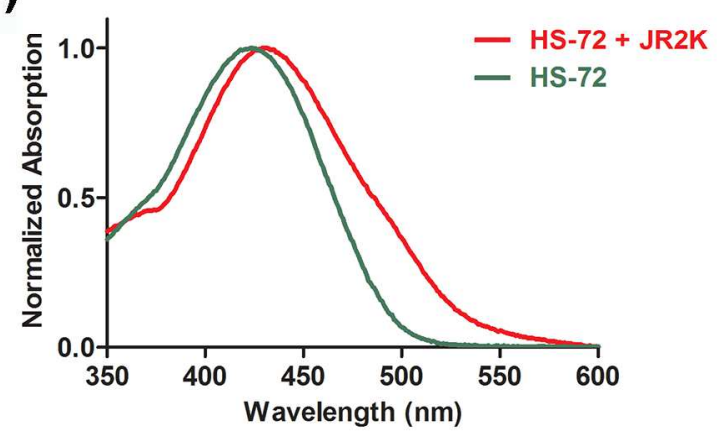

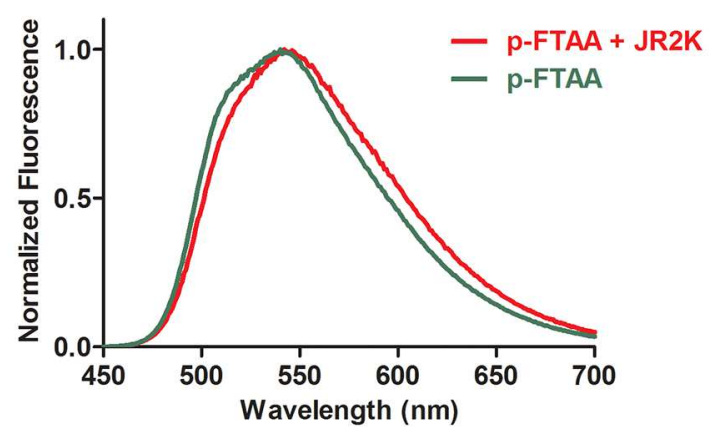
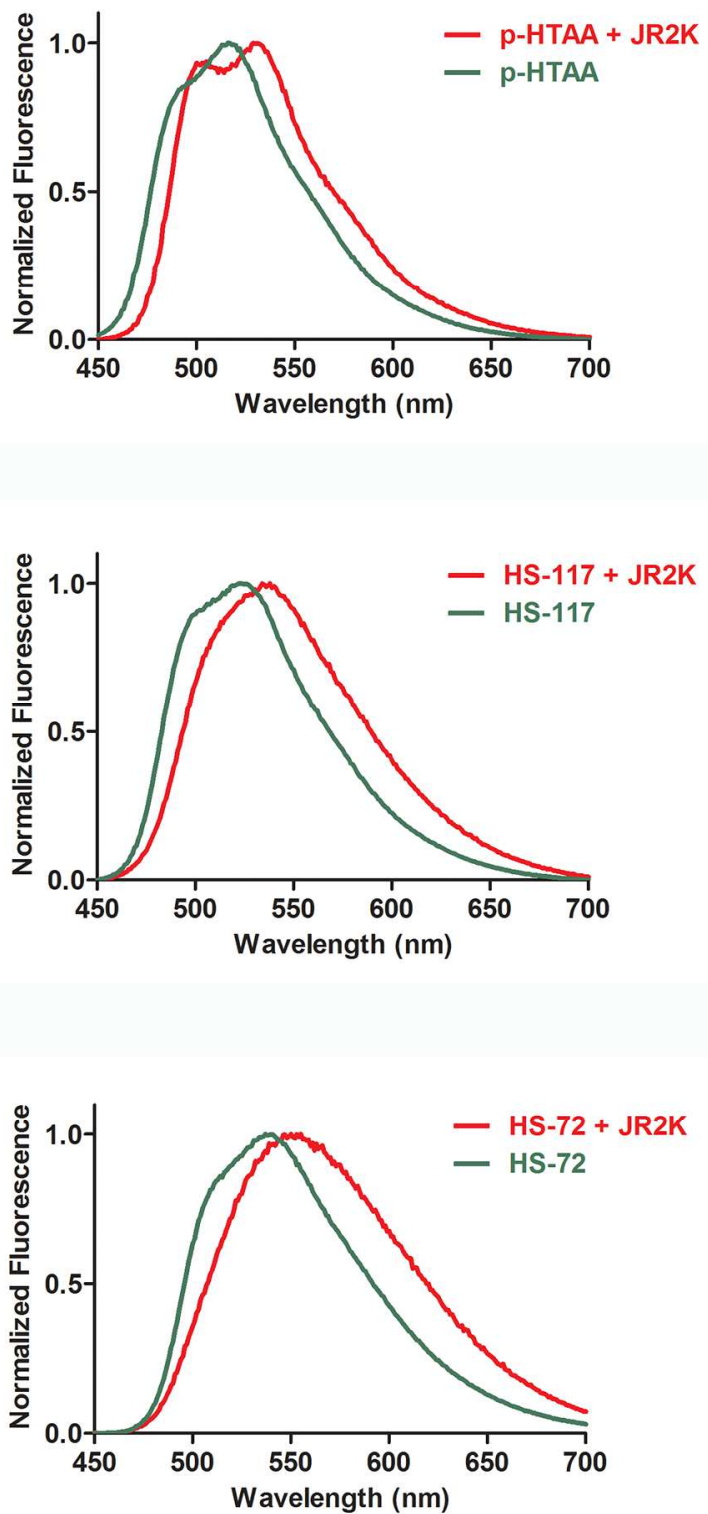

Figure 2. Optical properties of the LCOs mixed with JR2K. Absorption- (left panel) and emission spectra (right panel) of $30 \mu \mathrm{M}$ LCO (green) or $30 \mu \mathrm{M}$ LCO mixed with $30 \mu \mathrm{M}$ JR2K (red) in phosphate buffer (20 mM, pH 7.0). a) p-FTAA, b) p-HTAA, c) HS-117 and d) HS-72. 
a)
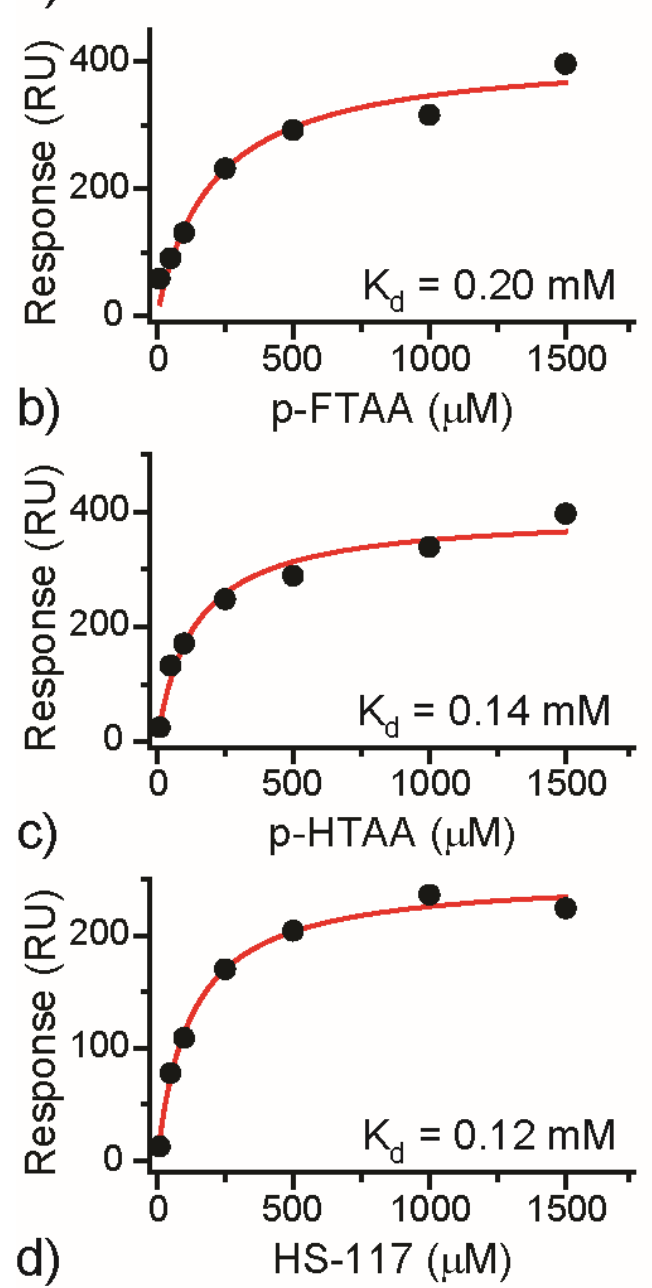

d)

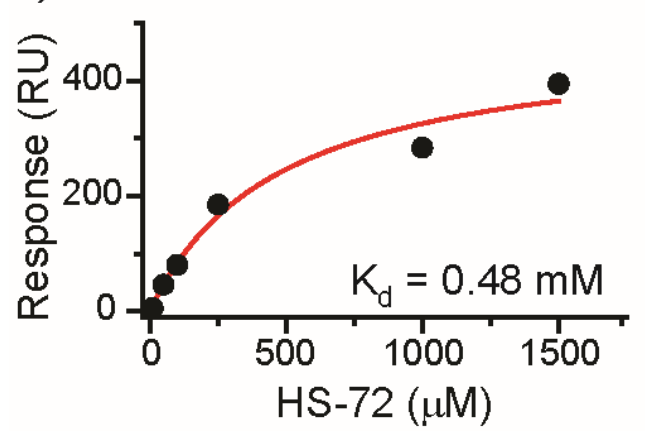

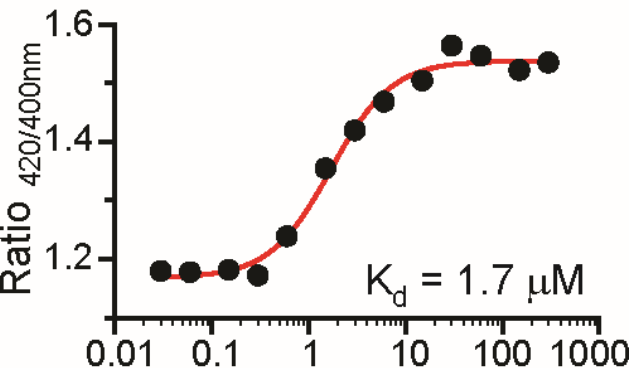

JR2K $(\mu M)$

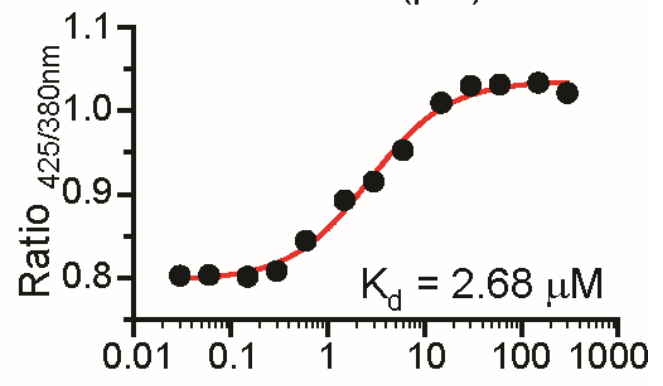

JR2K $(\mu M)$

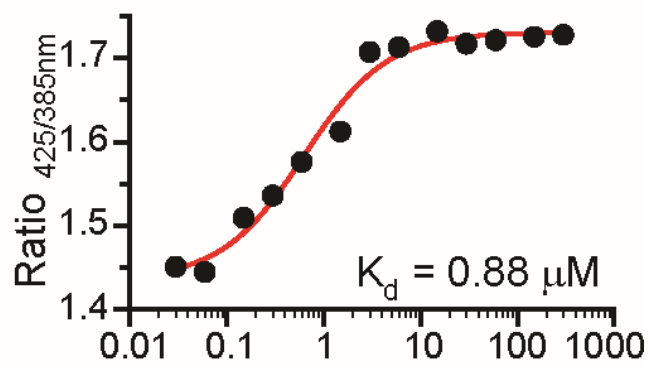

JR2K $(\mu \mathrm{M})$

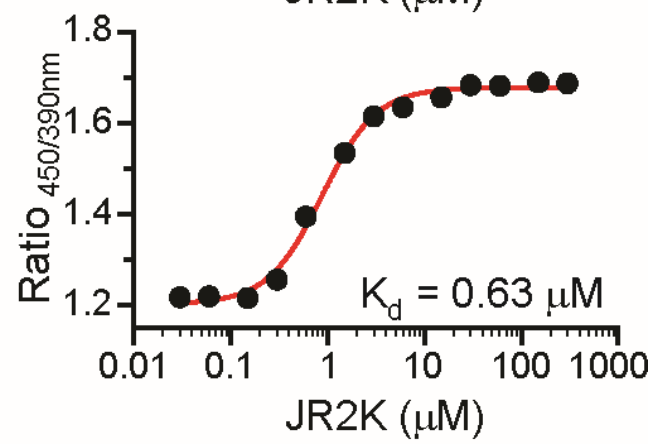

Figure 3. SPR derived steady state affinity models with fitted curves assuming a 1:1 ratio for the interaction of a) p-FTAA, b) p-HTAA, c) HS-117 and d) HS-72 with immobilized JR2KKAz (left panel). Binding curve showing the ratio of the intensity of the emitted light at the respective excitation maximum for bound LCO or unbound LCO against different concentrations of JR2K (right panel). Different concentrations of JR2K were mixed with 500 nM LCO in $20 \mathrm{mM}$ sodium phosphate, $\mathrm{pH}$ 7.0. 

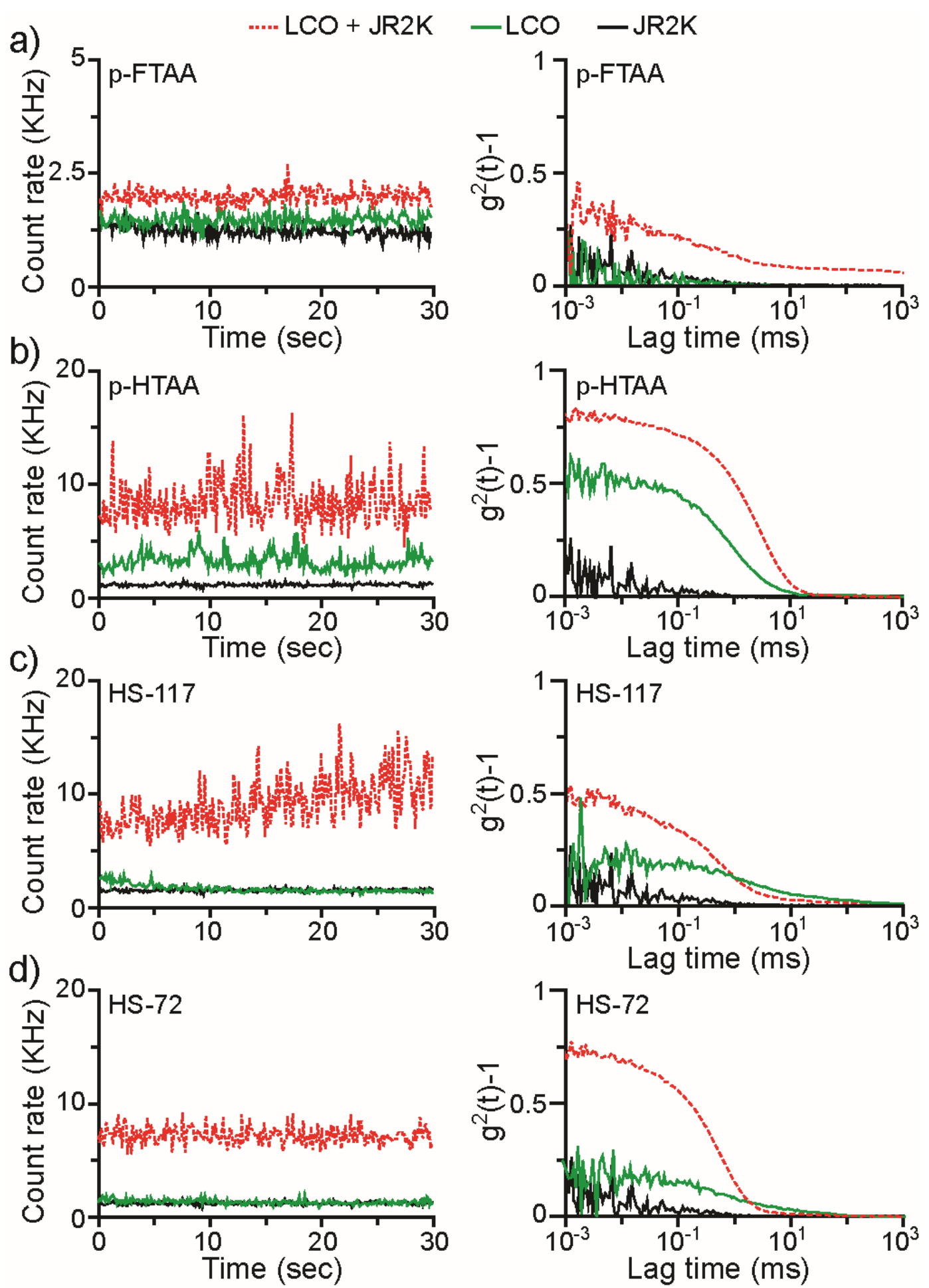

Figure 4. Scattering intensities (left panel) and resulting correlation functions (right panel) recorded by dynamic light scattering measurements of $30 \mu \mathrm{M}$ JR2K (black), $30 \mu \mathrm{M}$ LCO (green) and the mixture (red) in phosphate buffer $(20 \mathrm{mM}, \mathrm{pH} 7.0)$. a) p-FTAA, b) p-HTAA, c) HS-117 and d) HS-72. 


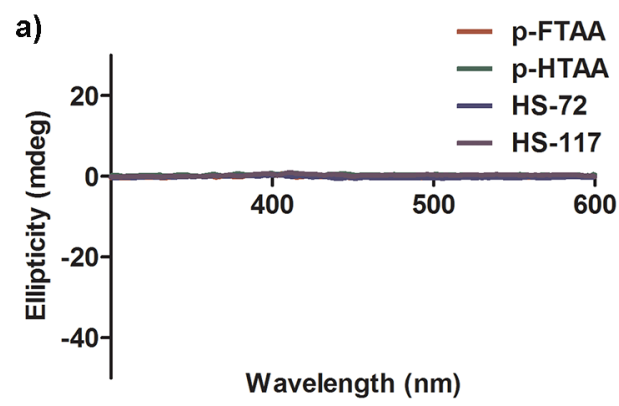

c)

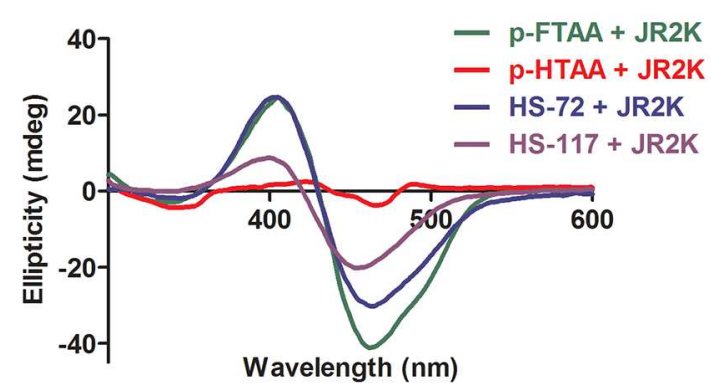

b)

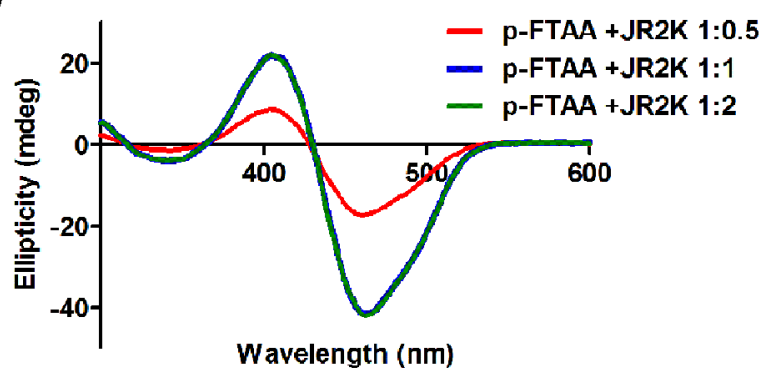

d)

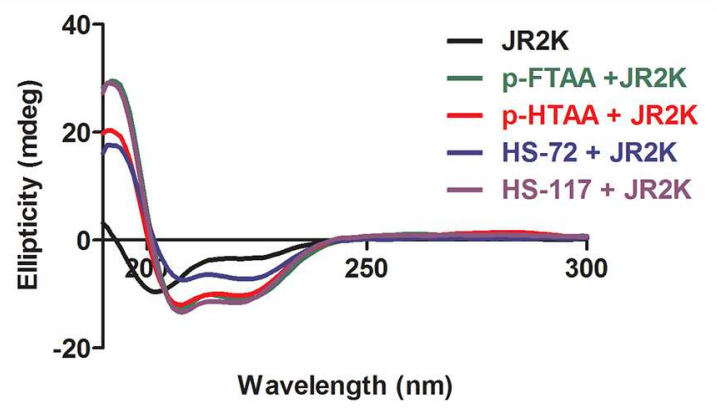

Figure 5. a) Circular dichroism (CD) spectra of $30 \mu \mathrm{M}$ of the respective LCO in $20 \mathrm{mM}$ sodium phosphate, $\mathrm{pH}$ 7.0. b) CD spectra of $30 \mu \mathrm{M}$ p-FTAA mixed with different concentrations of JR2K in $20 \mathrm{mM}$ sodium phosphate, $\mathrm{pH}$ 7.0. c-d) Circular dichroism (CD) spectra of $30 \mu \mathrm{M}$ of the respective LCO mixed with $30 \mu \mathrm{M}$ JR2K $20 \mathrm{mM}$ sodium phosphate, $\mathrm{pH}$ 7.0. The visible region (c) are showing the signal from the LCO, whereas the signal from JR2K are obtained in the UV-region (d). 

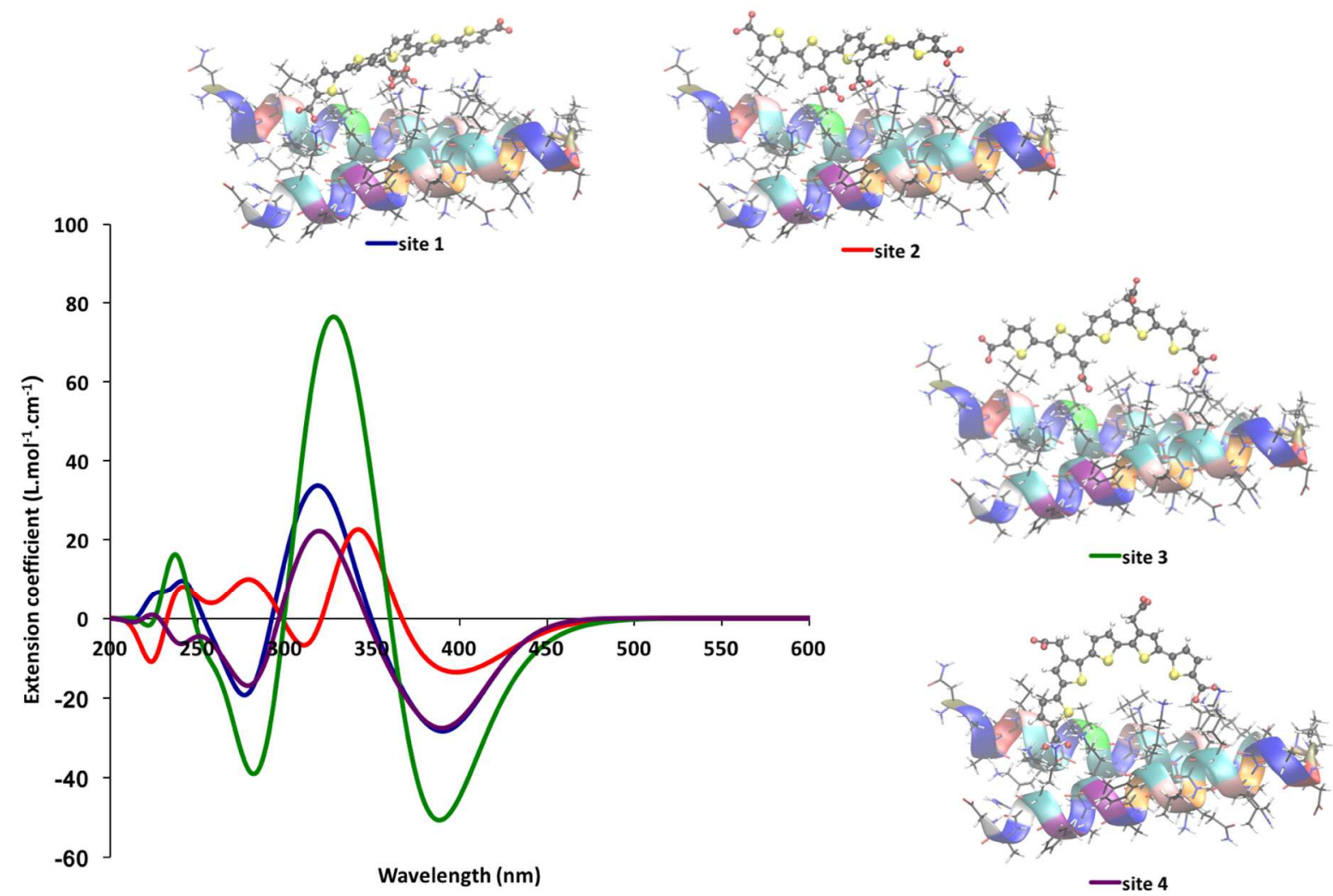

Figure 6. Theoretical CD spectra of p-FTTA for each of the four identified binding sites in JR2K. Spectra are obtained as averages for $150 \mathrm{MD}$ snapshots and calculated at the CAMB3LYP/6-31+G(d) level of theory. Illustrative conformations are provided for each binding site. 


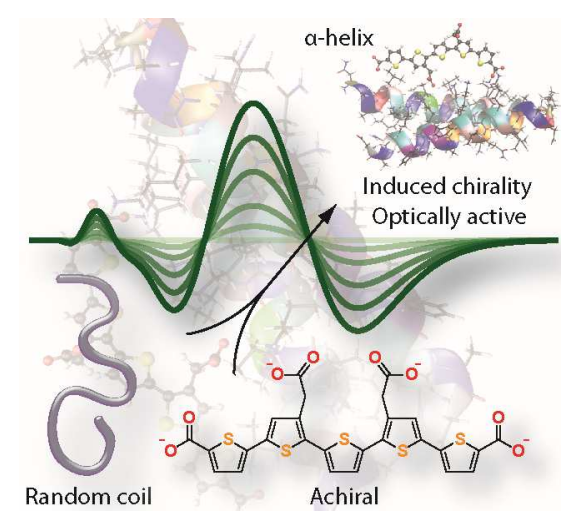

Table of contents (TOC) image

\section{TABLES}

Table 1. The four most probable binding sites for pFTAA in interaction with JR2K. When clearly identified, the Lysine residues in interaction with the four carboxylate moieties of pFTAA are listed. The averaged binding energies are reported in $\mathrm{kJ} /$ mole and interaction times in $n s$.

\begin{tabular}{|c|c|c|c|c|c|c|c|}
\hline \multirow[b]{2}{*}{ Site } & \multicolumn{4}{|c|}{ Residue interacted with $\mathrm{COO}^{-}$of pFTAA } & \multirow{2}{*}{$\begin{array}{l}\text { Time } \\
\text { spent } \\
(\mathrm{ns})\end{array}$} & \multicolumn{2}{|c|}{ Binding Energy } \\
\hline & $\begin{array}{l}\mathrm{COO}^{-} \\
\text {(1) }\end{array}$ & $\mathrm{COO}^{-}(2)$ & $\mathrm{COO}^{-}(3)$ & $\mathrm{COO}^{-}(4)$ & & Coulomb & $\mathrm{vdW}$ \\
\hline 1 & - & 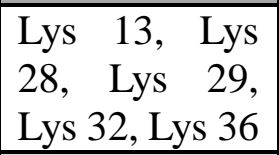 & $\begin{array}{l}\text { Lys 13, } \\
\text { Lys } 29\end{array}$ & Lys 19 & 160 & 4562.5 & 21.3 \\
\hline 2 & - & $\begin{array}{lcc}\text { Lys } & 13, & \text { Lys } \\
28, & \text { Lys } & 29, \\
\text { Lys } & 32 & \\
\end{array}$ & $\begin{array}{l}\text { Lys 13, } \\
\text { Lys } 36\end{array}$ & - & 310 & 4422.6 & 22.5 \\
\hline 3 & - & \begin{tabular}{lcc|} 
Lys & 13, & Lys \\
28, & Lys & 29, \\
Lys & 32 & \\
\end{tabular} & - & $\begin{array}{l}\text { Lys 6, Lys } \\
\text { 36, Lys } 39\end{array}$ & 140 & 4698.4 & 20.5 \\
\hline 4 & $\begin{array}{l}\text { Lys } 28, \\
\text { Lys } 29, \\
\text { Lys } 32\end{array}$ & - & - & $\begin{array}{l}\text { Lys 6, Lys } \\
\text { 36, Lys } 39\end{array}$ & 195 & 4763.1 & 22.1 \\
\hline
\end{tabular}




\section{Supporting Information}

Title: Distinct electrostatic interactions between a peptide and pentameric oligothiophenes generate optoelectronic materials with specific chiro-optical properties and architectural arrangement

Robert Selegård, Zeinab Rouhbakhsh, Hamid Shirani, Leif B. G. Johansson, Patrick Norman, Mathieu Linares, Daniel Aili and K. Peter R. Nilsson*

a)

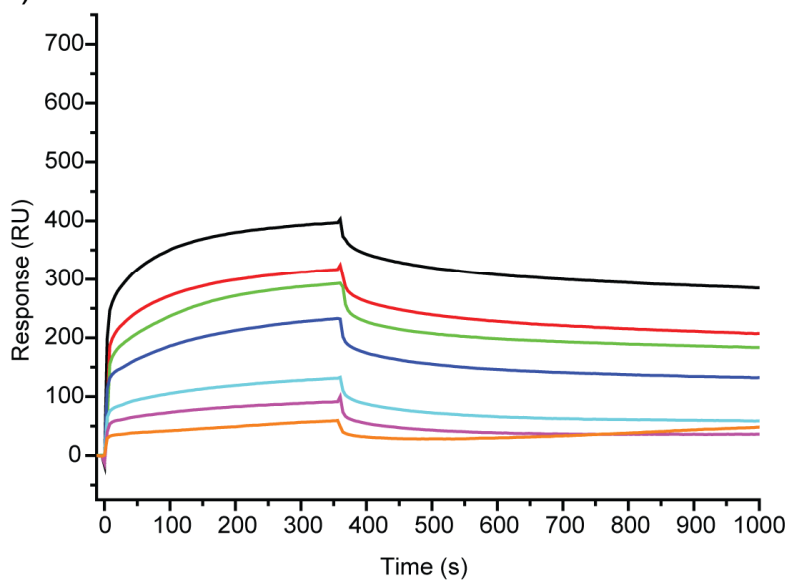

c)

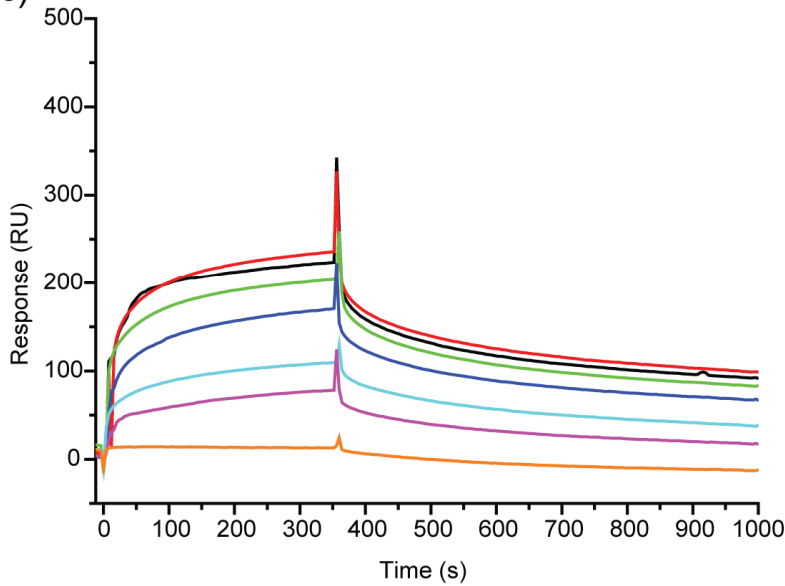

b)

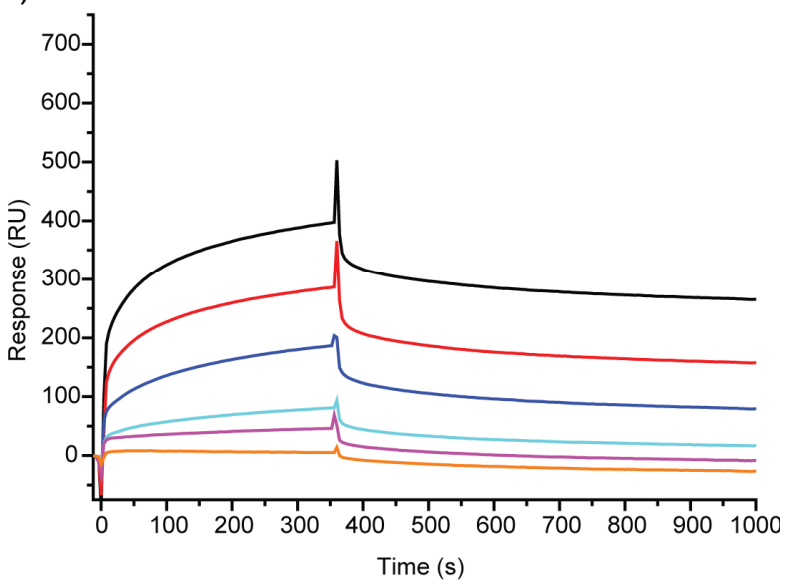

d)

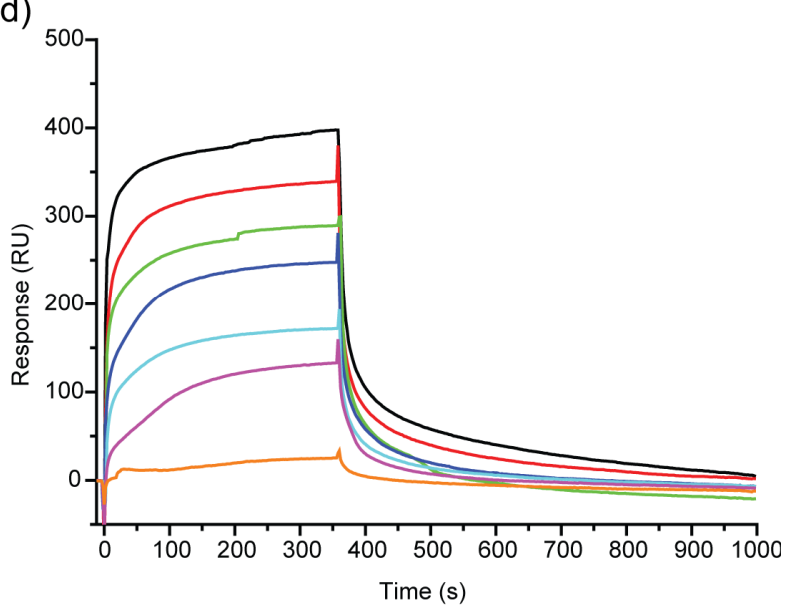

Figure S1. SPR sensograms reflecting the interactions between a) p-FTAA, b) HS-72, c) HS117 and d) p-HTAA with immobilized JR2KK-Az. The sensograms were reference subtracted, causing the discontinuities a $\mathrm{t}=0$ and $\mathrm{t}=360$ of the LCO pulses which were in the concentration interval of $10 \mu \mathrm{M}-1500 \mu \mathrm{M}$. 


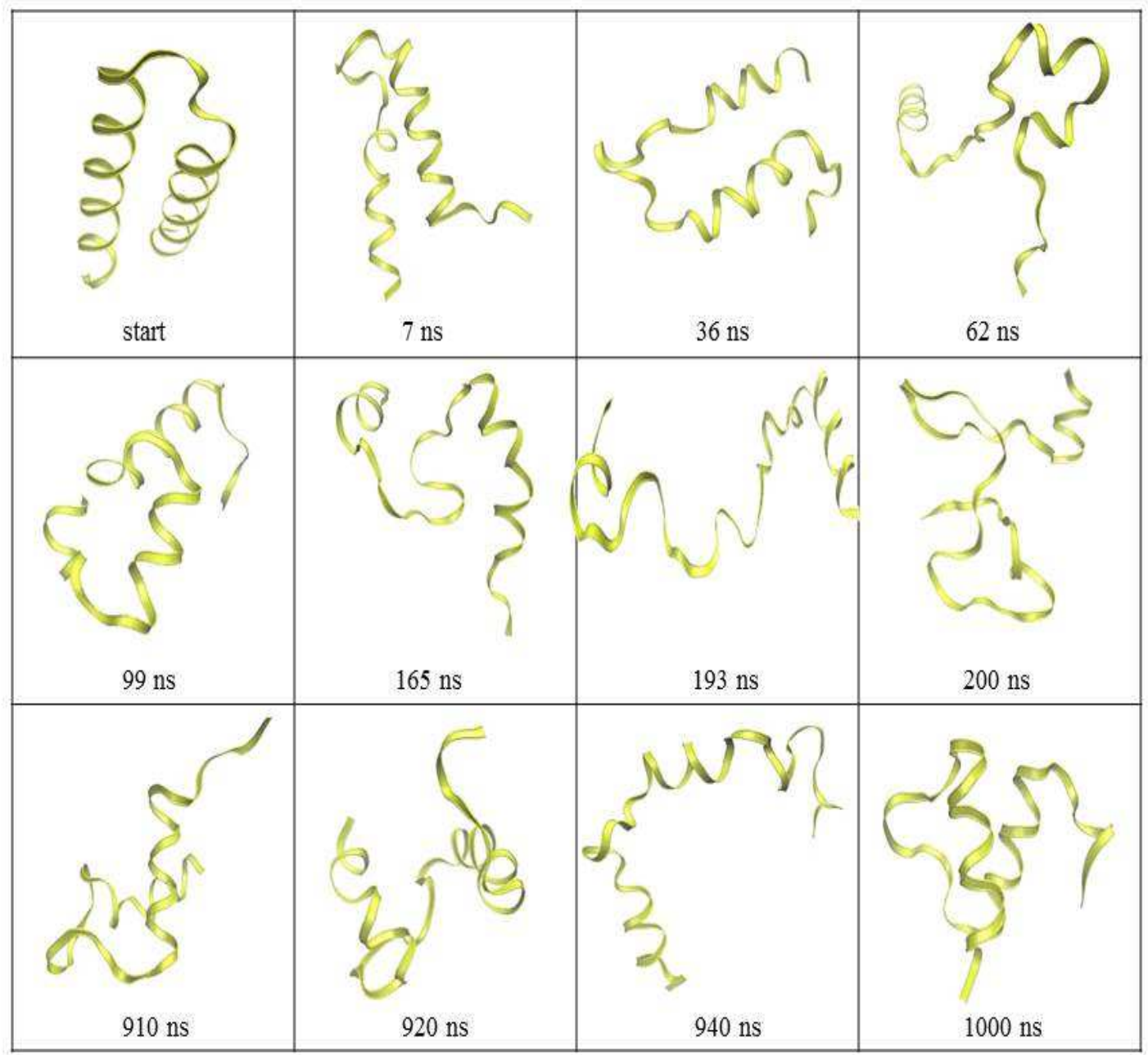

Figure S2. Snapshots of JR2K at different time point during MD simulation. 

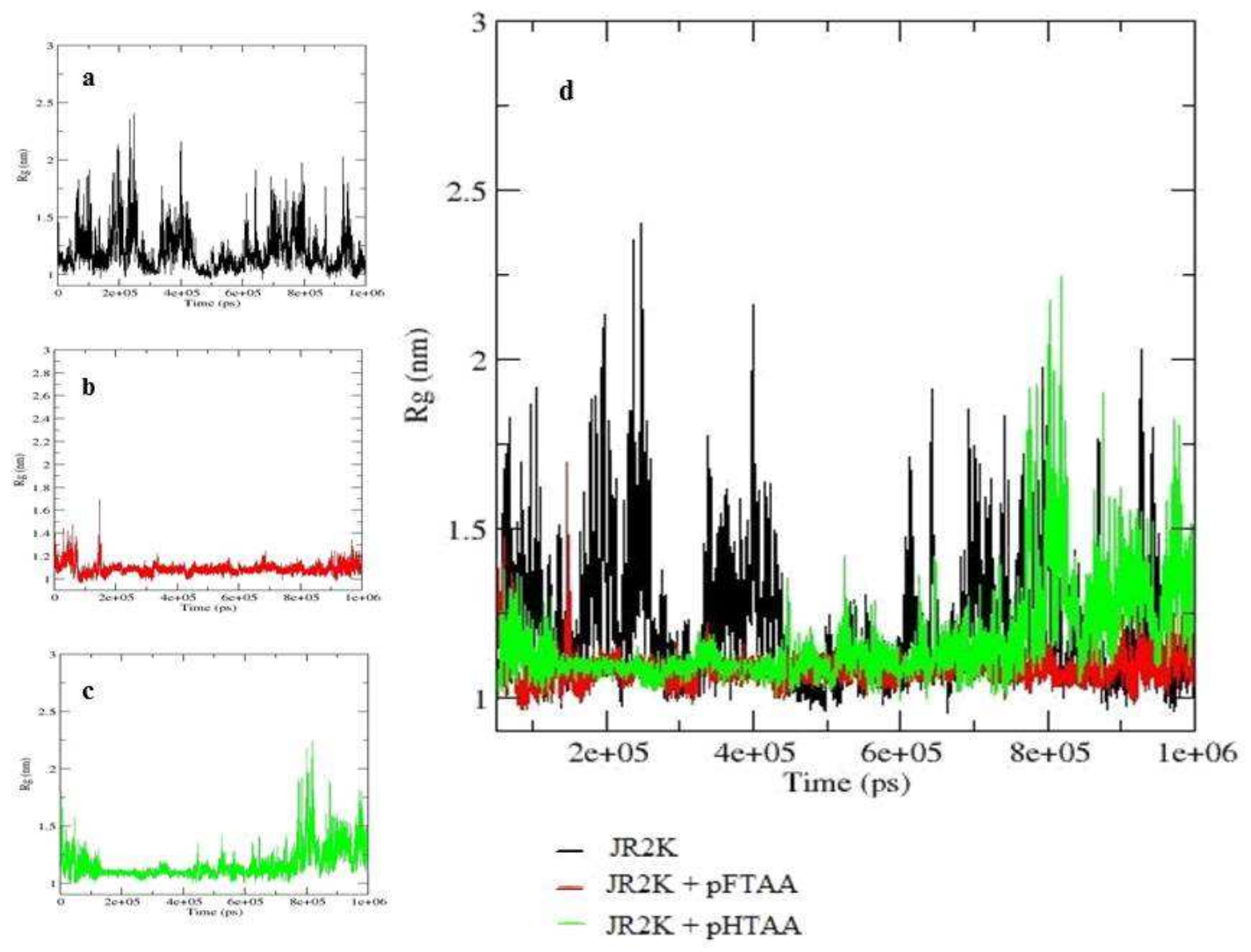

Figure S3. Time evolution of the radius of gyration ( $\mathrm{Rg}$ ) during $1 \mu \mathrm{s}$ of MD simulation of (a) JR2K, (b) JR2K-p-FTAA complex, (c) JR2K-p-HTAA complex, and (d) JR2K and JR2K-LCOs complexes. 


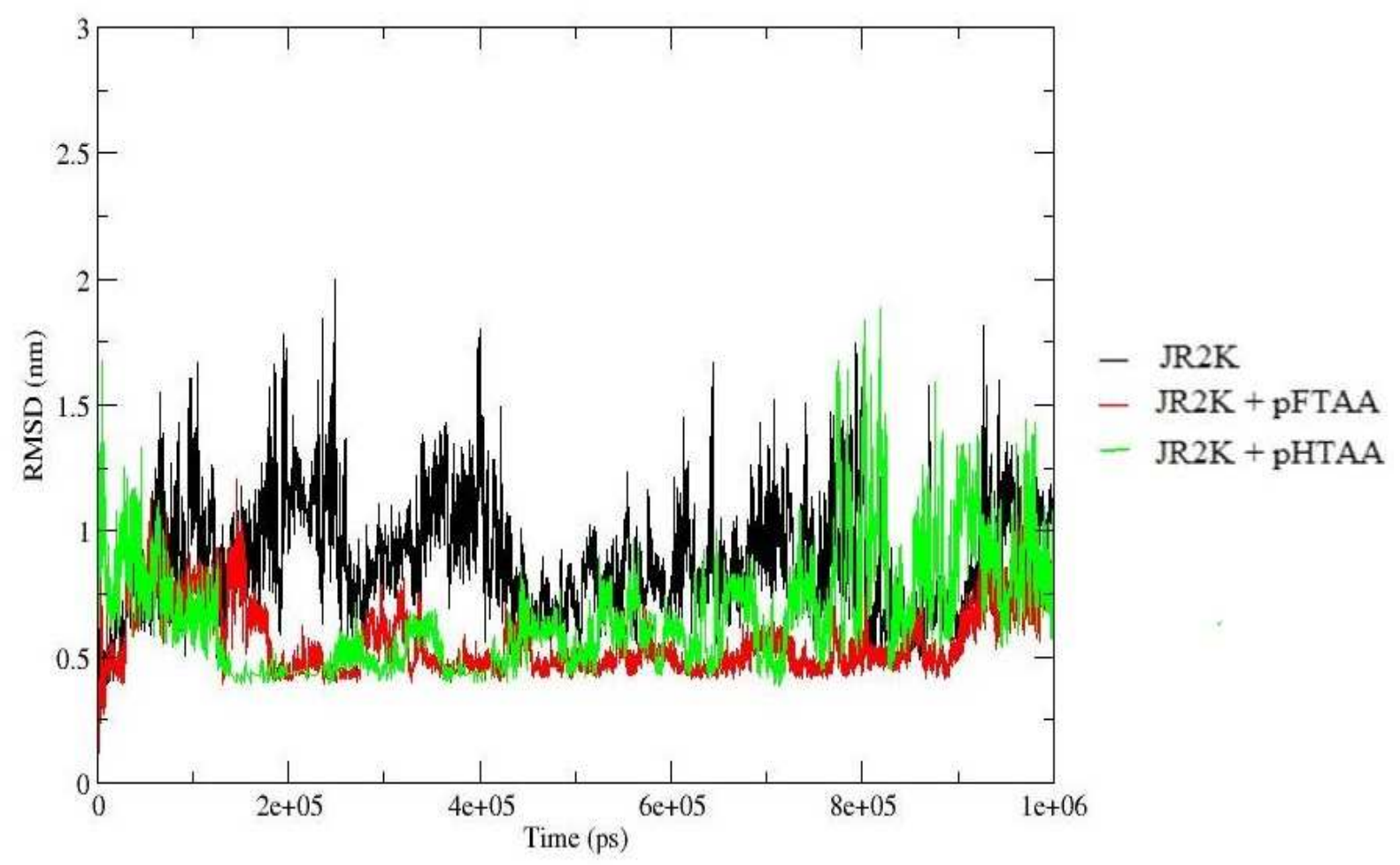

Figure S4. The RMSDs of $\mathrm{C} \alpha$ are shown as a function of time for JR2K and JR2K-LCOs complexes at $300 \mathrm{~K}$. 